\title{
Eco, U., (2019). Devlerin Omuzlarında (Milano Dersleri). (Eren Yücesan Cendey, Çev.). İstanbul: Doğan Kitap. 390 sayfa. ISBN: 978-605-09-6046-4
}

Süleyman YiĞíT' (1)

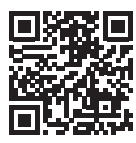

1PhD Student, Muğla Sıtkı Koçman University Institute of Social Sciences, Department of Turkish Language and Literature, Muğla, Turkey ORCID: S.Y. 0000-0003-4302-5200

\section{Corresponding author:}

Süleyman YiĞiT,

Muğla Sıtkı Koçman Üniversitesi, Sosyal Bilimler Enstitüsü, Türk Dili ve Edebiyatı Anabilim Dalı, Muğla, Türkiye

E-mail: suleymanyigit16@hotmail.com

Submitted: 09.10.2020

Revision Requested: 09.11.2020

Last Revision Received: 11.11 .2020

Accepted: 05.12.2020

Citation: Yigit, S. (2021). Devlerin

omuzlarında (Milano dersleri). [Umberto Eco, tarafından yayına hazırlanan Devlerin omuzlarında (Milano dersleri) başlıklı kitabın değerlendirmesi]. Litera, 31(1), 453-463. https://doi.org/10.26650/LITERA2020-808520

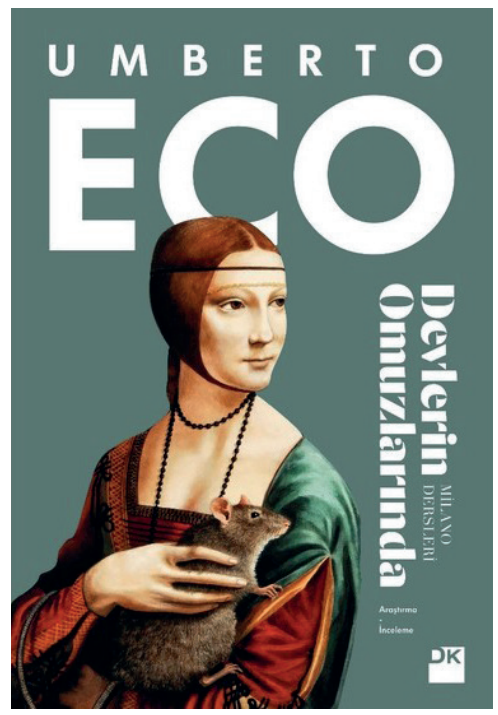

Umberto Eco'nun Milano'da yapılan sanat ve kültür festivali Milanesiana için hemen hemen her yıl hazırladığı 12 dersi bir araya getiren kitap Türkçeye Eren Yücesan Cendey tarafından çevrilmiştir. Yazarın diğer pek çok kitabı gibi Doğan Kitap tarafından 2019 yılı Mart ayında yayımlanmıştır. Eserin kapağında Milano Dersleri ibaresine de yer verilmiştir. 
Milanesiana festivali Elisabetta Sgarbi yönetiminde 2000 yılında kurulan, edebiyat, sinema, müzik, sanat, bilim ve felsefede büyük bir "mükemmellik laboratuvarı" olarak önerilmiş projedir. Proje kapsamında her yıl alanında Nobel ve Oscar başta olmak üzere, uluslararası alanda ödül kazanan isimler bir araya getirilmektedir. Başlangıçta sadece edebiyat, müzik ve sinema ile sınırlı olan festival zamanla bilim, sanat, felsefe, tiyatro, hukuk, ekonomi gibi alanları da içine alacak şekilde genişletilmiştir. Festival için 2008 yılından itibaren her yıl özel bir tema belirlenmiştir. Projenin 2019 yılındaki teması ise "umut"tur. Umberto Eco 2001 yılından 2015 yllına kadar (2002 ve 2014 hariç) her yıl festivale katılmışıı'.

Katılığı festivallerde sunduğu dersler kronolojik sıra gözetilerek esere alınmıştır. Kitabın başında yer alan "Italyan Yayıncının Sunuşu" başlıklı bölümde ifade edildiği üzere 12. ders "Kutsal Olanın Temsili" 2009 Milanesiana festivali için hazırlanmış, ancak festivalde sunumu yapılmadığı için son sıraya konulmuştur. Ayrıca U. Eco'nun festivalde sunduğu ilk ders olan kitabın da ilk sırasına konulan "Devlerin Omuzlarında" başlığı dışındaki tüm başıklarda görsellere de yer verilmiştir (2019, s. 11). Bu çerçeveden bakıldığında U. Eco'nun her yıl bir konuyla, 2009 yılında iki konuyla katıım sağladığı görülmektedir. 2009 yılındaki festivalin teması kitapta belirtilmemiştir. Festival için kurulmuş olan internet sitesinde ise tema "nesnelerin özüne dokunan her şey gibi görünmez: karmaşık ve basit" olarak belirlenmiştir. Bunun yanında 2003 ve 2004 yıllarında festivale katıldığı bilinmekle birlikte konuşma yapıp yapmadığı bilinmemektedir.

Kitapta yer alan dersler sırasıyla şöyledir:

- Devlerin Omuzlarında (2001)

- Güzellik (2005)

- Çirkinlik (2006)

- Mutlak ve Göreceli (2007)

- Alev Güzeldir (2008) -Tema: Dört Element

- Görünmez Olan (2009) -Tema: Görünmez

- Paradokslar ve Aforizmalar (2010) -Tema: Paradokslar

- Hatalı Bilgi Vermek, Yalan Söylemek, Sahtecilik Yapmak (2011) -Tema: Yalanlar ve Gerçeklik

1 Festival hakkındaki bilgiler http://www.lamilanesiana.eu/edizioni/2019/storia.html (e.t. 10.09.2019) adresinden alınmıştır. 
- Sanatta Bazı Kusurlu Biçimler Üzerine (2012) -Tema: Kusur

- Sır Hakkında Bazı Açıklamalar (2013) -Tema: Sır

- Komplo (2015) -Tema: Takıntılar ve Saplantılar

- Kutsal Olanın Temsili (2009) -Tema: Görünmez

Kitaptaki bölümlerden Mutlak ve Göreceli ile Alevler Güzeldir derslerine 2014 yılında yayımlanan Düşman Yaratmak ve Rastgele Yazılar adlı eserde yer verilmiştir. Ayrıca Güzellik dersinin genişletilmesiyle 2006 yılında Güzelliğin Tarihi, Çirkinlik dersinin genişletilmesiyle 2009 yılında Çirkinliğin Tarihi adıyla eserler yayımlanmıştır.

Devlerin Omuzlarında başlıklı kitaba ismini de veren ilk bölüm, Bernardo di Chartres'e ait bir aforizmadan yola çıkarak kaleme alınmışır². Kitabın arka kapak tanıtımında da yer verilen "Antik dönem insanları elbette bize oranla devdiler; ama bizler cüce olsak da onların omuzlarına oturarak, yani onların bilgeliğinden yararlanarak onlardan daha iyi görebiliyorduk" (Eco, 2019, s. 25) fikrini merkeze alarak devler ve cüceler, baba ve oğul, eski ve yeni arasındaki çatışma irdelenmiştir. Bu bağlamda Oedipus Kompleksi olarak bilinen "babayı öldürmek" fikri üzerinden hareket edilmiştir. Bernardo di Chartres'in düşüncesinin oluşumuna kadar geçen süreç irdelenmiş, onun fikrinden hareketle yüzyıllar boyunca söylenenlere yer verilmiş, konu hakkında çeşitli eserler önerilmiştir. Kutsal anlatılardan itibaren görülen babanın oğlu, oğlun babayı öldürmesi dersin sunulduğu 2001 yılına kadar çeşitli örnekler üzerinden güncellenerek açıklanmıştır. Buna göre çok eski tarihlerden itibaren geçirilen kültürel, sosyal, siyasi değişimlerin de etkisiyle zaman zaman babanın, zaman zaman dedenin, zaman zaman dededen yardım alarak babanın öldürülüşü kuşak çatışmaları üzerinden anlatılmıştır. Kuşak isyanlarının sonuncusu ise 68 kuşağıdır. Kitle iletişim araçlarının yaygınlaşmasıyla standart bir modelin önerilmediğini, bir çoktanrılılık oluşturulduğunu söyleyen U. Eco, bunun da babaları oğullarından ayırdığını, oğulları ata cinayetine, babaları da Satürn (aşağılık) kompleksine sevk ettiğini ifade etmiştir. Yeniliklerin ileri yaşlı kişiler tarafından sunulduğunu, ancak gençler tarafından kullanıldığını, bu yüzden bazen babalar ve oğulların bu noktada birbirlerine isyandan vazgeçtiklerini dile getiren U. Eco, bu durumun cücelerin başka cücelerin omuzlarında oturması

2 Söz konusu aforizmanın ortaya çıkışı konusunda birçok çalışma mevcuttur. U. Eco, bu çalışmalar arasında Edouard Jeauneau'nun Devlerin Omuzlarındaki Cüceler (1969), Robert Merton'un On the Shoulders of Giants (1965), John of Salisbury'nin Metalogicon, William of Conches'in Glosse a Prisciano'yu saymışıtır. Bunun yanında söz konusu ibarenin rastlandığı çeşitli eserlerin ismini anmıştır. Pek çok kişi tarafından kullanılan ve kökeni konusunda net bir fikir birliğine varılamayan aforizma Ortaçağ'ın başında popüler hâle gelmiştir ve U. Eco'nun eserine göre Bernardo di Chartres'e atfedilir (2019, s. 23-25). 
anlamına geldiğini, ilerleyen dönemde devlerin cücelerin omuzlarına binmeye hazırladıklarını söyleyerek bölümü tamamlamıştır.

İkinci bölüm Güzellik başlı̆ını taşımaktadır. Bu başlık altında yazar 1954 yılında Aquinolu Aziz Tomasso'nun fikirlerinden yola çıkarak bir tez kaleme aldığını ve güzellik konusuna adım attığını ifade eder. Ardından 1962 yılında güzellik tarihine adadığı resimli bir kitap projesine başladığını ancak bu kitabı bastıramadığını söyler ki bu eser 50 yıllık bir çalışma ile yayımlanmıştır (Eco, 2006). Bu girişin ardından güzelliğin hiçbir zaman mutlak olmadığı, bir başka ifadeyle göreceli olduğu fikri üzerinden sözlerine devam eder. Yazara göre güzellik genellikle sanatsal güzellikle eşdeğer tutulmuştur ve uzun yıllar güzellik konusunda üç kriter aranmıştır. Bunlar orantı, ışıltı/claritas ve bütünlüktür. Zaman içinde yapılan çalışmalar güzelin her zaman orantı ve ışı ile açıklanamayacağını ortaya koymuştur. Edmund Burke ile birlikte güzel, yüce ile eşdeğer tutulmuştur. Yine neoklasik dönemle birlikte gotik mimariye hayranlığın başlaması oransız ve düzensiz olanı ön plana çıkarmıştır. XX. yüzyılın ikinci yarısı itibariyle avangart sanatların güzelliği ile tüketimin güzelliği arasında dramatik bir savaş başladığını ifade eden U. Eco avangart sanatı, güzellik sorununu ele almayan, o ana dek saygı gören tüm estetik yargıları yıkan bir fikir olarak tanıtmıştır. Ayrıca avangart sanatın dünyayı başka bir gözle yorumlamayı öğrettiğini söyler. Bunun yanında soyut sanat olarak ortaya çıkan görüşün ise sıradan insanın güzelliğe sahip olamayacağı fikrini savunduğunu ifade etmiştir. Sanat adı altında ritüel tadında ayinler ile devasa kalabalıkların konserlerde ışık oyunları ve son derece yüksek ses altında 'birlikte olma' hallerinin dışarıdan bakanlar için güzel olabileceğini de söylemiştir. Kitle iletişim araçlarının önerdiği güzellik modeli ise çoktanrılı bir güzellik anlayışıdır. Bu bölümün son kısmında güzelliğin göreceli oluşunu bir kenara bırakırsak, "küçük de olsa güzelliğin ortak noktası yok mudur?" sorusuna cevap arayan U. Eco güzellik konusundaki farklı metinlerin bir araya getirilmesiyle bu ortak noktaların bulunabileceğini söyler. Bu cevap üzerinden iyi ve güzel kavramları arasındaki ilişkiye değinir. Ardından güzellik ve arzu arasında da bağlantı kurarak güzellik konusuna bir son verir.

Üçüncü bölüm Çirkinlik başlığını taşımaktadır. Bu başlık altında da diğer başlıklarda olduğu gibi konuya panoramik bir bakış atılmıştır. Bölüm boyunca çirkin kavramı ele alınırken güzel kavramından faydalanılmıştır. Öncelikle çirkin konusundaki literatüre göz atan U. Eco konu hakkındaki tek eserin Karl Rosenkranz'ın 1853'te kaleme aldığı Çirkinin Estetiği (2018) adlı eser olduğunu ifade etmiştir. 
Ardından çirkinin ne olduğu üzerinde durulmuş ve çirkinin de güzel gibi göreceli bir kavram olduğu söylenmiştir. Çirkin kavramının zaman içinde geçirdiği değişimi ise Platon ile başlatan U. Eco, Platon'un çirkini temsil etmekten kaçınmayı öğütlediğini, bunun Aristoteles'ten sonra çirkinin de güzelce temsil edilebileceği, bu yolla güzelliğin yüceltilebileceği şeklinde değiştiğini ifade etmiştir. Illerleyen dönemde Schiller ise insanın doğası gereği hüzünlü, korkunç, hatta dehşet verici olanın cazibesine kapıldığını söylemektedir. Acı ve korku sahnelerinde insanın hem itilip, hem de bir şekilde çekildiğini, hayalet hikâyelerinin, dinleyenlerin tüylerini diken diken etse de tekrar tekrar anlatılığını ve dinlendiğini ifade etmiştir. Bunun yanında işkence sahnelerine de değinen $U$. Eco, işkence sahnelerinin, işkenceyi tasvir etmekten zevk alındığı için anlatıldığını savunur. Hâlbuki uzun bir işkence tasvirinin yerine suçlu öldürüldü, demek yeterli olacaktır. Görüşlerine yer verilen bir başka isim Hegel'dir. Hegel, çirkinin sanat tarihine Hristiyanlık ile girdiğini iddia etmektedir. Çile çeken İsa Yunan güzellik formlarıyla temsil edilmeyeceği için çirkinleşen İsa'nın ortaya çıkmıştır. Çeşitli kişilerin görüşlerinden sonra genel bir bakışa geçen U. Eco Ortaçağ'ın canavarlar açısından oldukça zengin olduğunu, tüm bu hilkat garibelerinin Tanrı tarafından doğaüstü olaylara anlam yüklemek için yaratıldıklarını söylemiştir. Ayrıca her canavarın ruhsal bir anlama sahip olduğunu söyleyen U. Eco, Ortaçağ'da canavarların çirkin değil, ilginç ve masalsı görüldüklerini ifade etmiştir³. Bu noktada teratoloji ve fizyognomi (yüz okuma) kavramlarına da değinilmiştir. Ardından çeşitli eserlerden zenci ve Yahudi gibi ötekileştirilen insanların ve Deccal'in tasvirleri alıntılanmıştır. Tarihi akışın bir noktasında çirkine, anlayışla ve merhametle yaklaşan eserler kaleme alınmıştır. Bunun ilk örneği olarak Shakespeare'in Fırtına adlı eserindeki Caliban karakteri gösterilmektedir. XVII. yüzyılda Cyrano ile Frankenstein ortaya çıkmıştır. XVIII. yüzyıldan sonra çirkin ve lanetlenmiş olanlar vardır. Buharın ve makineleşmenin insan hayatına girmesiyle modern kentin çirkinliği üzerinde durulmaya başlanmıştır. Sanayinin bu çirkinliğine tepki olarak saf estetizme kaçış anlayışı doğmuştur. Klâsik anlayışa tamamen zıt olarak avangart hareketin ortaya çıktığı, bunun kitleselleşmesi ile kitschin doğduğu söylenmiştir. Kitsch kavramı üzerinden camp kavramına da değinen U. Eco, son olarak kitle iletişim araçlarının gösterdiği güzellikler ve çirkinlikler üzerinde durarak konuyu nihayete erdirmiştir.

Dördüncü bölüm Mutlak ve Göreceli başlığını taşımaktadır. U. Eco öncelikle mutlak kavramının ne olduğunu kendine sorarak başlamaktadır. Bunun yanında mutlağa

3 Tıpkı Evliya Çelebi'nin Seyahatnâme adlı eserinde acayip ve garip başıkları altında anlattığı hilkat garibeleri(Özay Diniz, 2017) gibi düşünülebilir. 
yönelen sanatçılara ait görseller aradığını, çalışmaları esnasında mutlak kavramının, zıtlarından birini, görecelilik kavramını çağrıştırdığını söyler. Mutlak kavramı felsefe ansiklopedilerine göre bağlardan ve sınırlardan özgürleşmiş, başkasına hiçbir şekilde bağımlı olmayan, kendi nedeni ve açıklaması olandır. Bu anlamda Tanrı'yı çağrıştırmaktadır. Tanrı karşısındaki insan acizdir. Dante Cennet'in son bölümünde İlahi bakışlara bakabildiği anda ne gördüğünü anlatmaya çalışsa da dile getirebildiği sadece güçsüzlüktür ve onu ifade edemediğini söyler aslında. Göreceliliğin, "bilme ve etkime alanında mutlak ilkeler kabul etmeyen her kavram" olarak tanımlandığını söyleyen U. Eco, özellikle kültürel görecelilik üzerinde uzun uzun durur.

Beşinci bölüm Alev Güzeldir başlığını taşımaktadır. 2008 yılında yapılan festivalin konusu Dört Element'tir. U. Eco, dört elementten ateşi, unutulmaya yüz tuttuğu için seçtiğini ifade etmiştir. Zira hava her gün solunuyor, su her gün içiliyor, toprak her gün çiğneniyor ancak insanın ateşle olan ilişkisi giderek azalıyor demektedir. Öyle ki ateşin işlevi farklı kaynaklara aktarılmaktadır. Örneğin ışık kavramı alevden alınmıştır. Artık sadece ocakta, kibritte, çakmakta ve mumda alev görülebilmektedir. Alevle insanın birebir ilişkisi azalmıştır. Bu girişin ardından ateş konusunda yapılan çalışmalara dikkat çeken U. Eco, bu konu hakkında en çok düşünenlerin başında Gaston Bachelard'ı göstermiştir ${ }^{4}$. Ateşin insan hayatındaki önemini psikanaliz yardımıyla anlattıktan sonra bu çalışmada ateşin kaba ve umursamaz anlamının peşine düşeceğini, ısıtan, can alan ateşin insanlar gözündeki anlamını didikleyeceğini dile getirmiştir. Buraya kadar olan kısım konuya bir giriş niteliğindedir. Bunu çeşitli başlıklar takip etmiş̧ir. Başlıklardan ilki İlahi Unsur Olarak Ateş'tir. Ateş ilk andan itibaren Tanrısal olanla bağdaştırılmıştır, bütün ilkel dinlerde ateş kültü bulunmaktadır. Kutsal kitaplardan genellikle Tanrı́nın görünür hâle gelmesi ateş iledir. Aristoteles, Herakleitos, Plotinos, Diogenes Laertus gibi isimlerin görüşlerine yer veren U. Eco, ikinci olarak Cehennem Ateşi başlığını vermiştir. Ateşin göklerden yeryüzüne yansıdığını, bunun yanında da yeryüzünden de fışkırarak ölüm saçtığını söylemiş ve bunun yanında ateşin hemen bütün dinlerde cehennemle bağdaştıııldığını dile getirmiştir. Üçüncü başlık Simya Ateşi'dir. Simya ateşi, ilahi ateş ile cehennem ateşi arasında konumlandırımaktadır. Simya işi ile uğraşanlar düşük metallerden altın elde etmeye yarayacak felsefe taşını elde etmeye çalışmaktadır. Bunun yanında simyanın söylenmeyen bir sır, sırların sırrı olduğu ifade edilmiştir. Dördüncü başlık Sanatın Nedeni Olarak Ateş'tir. Prometheus'un ateşi ve bilgeliği Hephaestus ve Athena'dan

4 Şeyh Galib'in Hüsn ü Aşk adlı eserinde Aşk'ın ateş denizini mumdan gemilerle geçmeyip, atı Aşkar ile aşması, Aşk'ın ateş üzerinde bir denetim kazanmasına da imkân sağlamıştır (Holbrook, 2008). 
kaçırarak insanlara verişi ile birlikte sanatın doğduğunu söylemiştir. İlahi özellik taşıyan ateşi eline geçiren insanoğlu ayrıcalıklı bir gücü eline geçirmiştir. Epifanik Deneyim Olarak Ateş başlığında sanatı eserinin ilahi yaratımla eş tutulduğu, bunun da şirki beraberinde getirdiği söylenmiştir. Walter Peter, Gabriele d'Annunzio ve James Joyce üzerinden örnekler verilmiştir. Bir diğer başlık Yeniden Canlandıran Ateş'tir. Ateşin Tanrısalığı, arındırıcılı̆ı̆, öldürmesi ve canlandırması ön plana çıkarılmıştır. Ölülerin yakılması yine bu çerçevede değerlendirilmiştir. Bu bölümün son başlığı Çağdaş Ekpyrosis Örnekleri'dir. Bütün savaş hikâyelerinde ateşin yok edici olduğu, atom bombasının patlamasıyla ateşin tüm insanlığı korkuttuğu ifade edilmiştir. Tüm bunların yanında havanın ve suyun kirlendiğini, ateşin ise gücünü koruduğunu söyleyen $\mathrm{U}$. Eco, ateşin Isı formunda yeryüzünü kuruttuğunu, mevsimleri alt üst ettiğini, buzulları eritip deniz seviyelerini yükselttiğini bunun da ilk ve gerçek ekpyrosise zemin hazırladığını söyleyerek bölümü tamamlamıştır.

Kitabın altıncı bölümü Görünmez Olan'dır. Bir alt başlık olarak Anna Karenina'nın Baker Sokağı'nda Oturması Neden Yanlıştır? şeklinde bir soru sorulmuştur. Görünmez olandan kasıt anlatılarda yer alan kahramanlar, kurmaca ve uydurmaca varlıklardır. Yazınsal dünyanın kahramanları yoktan yaratılmışlardır ve imgelerle değil sözlerle anlatıldıkları için görülemezler, ancak aramızda yaşarlar. Bir kurmaca metin okunurken okur ve yazar arasında anlaşma yapıldığını, yazarın gerçek bir şey anlatır-mış gibi yaptığını, okurun da ciddiye alır-mış gibi yaptığını ve bu yolla bir metin içinde doğan kahramanın metin dışında yaşayabildiğini dile getirmiştir. Gerçek hayattaki bir tarihi olayın ortaya çıkan yeni kanıtlarla değişiklik gösterebileceğini, ancak kurmaca dünyadaki bir olayın kesinlikle değişmez olduğunu ileri süren U. Eco, Hitler'in nasıl öldüğü her gün çıkan bilgiyle değişir, ancak Anna Karenina'nın kendini tren raylarına atarak kendini öldürüşü kesindir şeklinde örneklendirmiştir. Bunun yanında Sherlock Holmes'in Spoon River kıyılarında, Anna Karenina'nın Baker Sokağı'nda oturmasının da yanlış olacağı ifade edilmiştir. Zira iki kahraman tam tersi mekânlarda oturmaktadır. Söz konusu bölümde U. Eco açık olarak ifade etmese de özdeşleşme kavramından söz etmektedir. Okuyucu Genç Werther'in kendini öldürdüğünü gerçekten inanmaktadır, hatta ardından intihar edenler olmuştur. Bunun nedeni okurun kendini kahramanla özdeşleştirmiş olmasıdır. Sinema filminde oyuncuya değil, kahramana âşık olunması da bununla alakalıdır. Okur, kahramanla o kadar özdeşleşir ki kahramanın kaderini değiştirebilmesi ümit eder. Ancak, bugün bilgisayarlar romanları yeniden ve istenilen şekilde kurgulama imkânı vermesine rağmen okur herhangi bir değişiklik yapmak istemez şeklinde bölüm tamamlanır. 
Yedinci bölüm Paradokslar ve Aforizmalar adını taşımaktadır. Giriş olarak niteleyebileceğimiz kısımda paradoks, paralogizm, insolubilia, antinomi gibi kavramlara açıklık getirilmiştir. Ardından Epimenides'in yalan paradoksu, Zenan'a atfedilen Akhilleus ve kaplumbağa paradoksu, Bertnard Russell'in berber paradoksu, Aulus Gellius'un aktardığı Protagoras ve Euathlos paradoksu, Diogenes Laertius'un timsah paradoksu okuyucuya aktarılmıştır. Raymond Smullyan'ın derlediği mantıklı paradokslardan örnekler verilmiştir. Retorik paradoks konusuna da açıklık getiren yazar, bu kavramın aforizmayı çağrıştırdığını söyleyip, aforizma ve paradoksu ana hatlarıyla karşılaştırma yoluna gider. Paradoks ve aforizma denildiğinde ilk akla gelen isim olarak Oscar Wilde gösterilir ve onun eserlerinden özellikle Dorian Gray'in Portresi'ndeki Lord Wotton'un aforizmalarından uzun örneklere yer verilir. Bu bölümü de internette yaygınlaşmış klişelerin toplandığı bir eseri söyleyip Karl Kraus'un ünlü paradokslarına yer vererek tamamlamıştır.

Kitaptaki sekizinci bölüm Yalanlar ve Gerçeklik temalı festivalde sunulan Hatalı Bilgi Vermek, Yalan Söylemek, Sahtecilik Yapmak adlı yazıya ayrılmışır. Öncelikle yalan konusunda bir giriş yapılmıştır. Yalanı, dil felsefesi ve mantığın yanı sıra, ahlak ve siyasi bilimler tarihinin de en çok tartışılan konularından biri olarak gören U. Eco, Maria Bettetini'nin Yalanın Kısa Tarihi ve Andrea Tagliapitra'nın Yalanın Felsefesi adlı eserleri önerir. Yalan söylemek olgu olarak kabul edilen bir şeyin tam tersini söylemektir. Bu çerçevede edebi eserlerin mevcut dünyadan farklı olan bir dünyada olgu olanı anlattığını, yalanın gerçek dünyada olgu olarak var olmayan şeyi anlatma yoluna gittiğini söyleyen U. Eco, bu yüzden edebi eserlerin yalan olmadığını söyler. Bu bölümde de alt başlıklara yer verilmektedir. Bunlardan ilki Yalan Ahlakı'dır ve yalanın etik sorunları üzerine eğilir. Yalanın On Emir'den biri ile yasaklandığı, siyasette yalan, doğrucuların yalana yaklaşımı gibi konular ele alınmışır. İkincisi Barok Gizlenme'dir. Gerçeklerin gizlenmesine değinilmiştir. Galileo'nun mahkum edilmesinden sonra Dünya ya da Işı Üzerine Inceleme adlı eserini yayımlamaktan vazgeçen Descartes örnek olarak verilmiştir. Bir diğer alt bölüm Edebi Kurmaca başlığını taşımaktadır. Yukarıda da ifade edildiği gibi edebi kurmaca bir yalan değildir. Edebi kurmaca biri inansın ya da biri zarara uğrasın diye sahte bilgi verilmez. Olası bir dünya yaratılır ve okur buraya davet edilir. Okur buradaki her şeye inanır. Dördüncü alt başlık ise Onursuzluk'tur. Buraya kadar anlatılan yalanların aldatan ve aldatılan olmak üzere çift yüzlü olduğunu dile getiren U. Eco bunun yanında bazı tek, bazıları üç yüzlü yalanlar da vardır, der. Tek yüzlü yalanda söz konusu olan onursuzluktur. Gerçeği bilen biri yalan söyler, bu yalana zamanla kendi de inanır. Üç yüzlü yalan ise bu bölümün bir diğer başlığı olan İroni'de 
ele alınmıştır. İroninin tanımı yapılmış ve ironiyi yapan, ironiyi anlamayan kurban ve kurbanın dışında ironiyi anlayan biri olmak üzere üçlü yüz tamamlanır. Bir diğer üç çehreli yalan için yeni bir başlığa yer verilmiştir. Bu Sahtecilik'tir. Bunu Ex Nihilo Sahtecilik, Özgünlük Kanıtları ve lyimser Bakış Açısı adlı üç alt başlık takip etmektedir.

Dokuzuncu bölümün başığı Sanatta Bazı Kusurlu Biçimler Üzerine'dir. Kusur, üzerine çok konuşulsa da, kavram olarak daima kusurlu kalma riskine sahiptir. Bu bağlamda konu hakkında Greimas ve Rita Levi-Montalcini'ye ait eserlere değinilir. Insan, Tanrıya göre kusurludur. Tanrı sürekli olarak yaratıcılığına devam edebilmek için bu yola başvurmuştur. Ardından Aziz Tomasso'nun güzellik konusundaki görüşlerine yer verilmiştir. Tomasso güzelliğin ön şartları arasında la propotio, la claritas ve integritas'ı sayar. İntegritas bütünlük demektir. Bu durumda bütünsel anlamda bozuk olan çirkindir. Cüceler ve sakatlar kusurludur. XIII. yüzyılda Guillaume d'Auvergne üç ya da tek gözlü olanı aşağılık olarak kabul ederdi. Başlık altında dikkat çekilen bir başka husus kıyamet günü insanların nasıl dirileceği problemidir. Eksik ya da kusurlu da dirilebileceğini düşünenlere karşın, Aziz Tomasso insanların uzuvlarının tam olarak doğacağını iddia etmektedir. Ayrıca insan, bağırsakları iğrenç atıklarla dolu olarak değil soylu bir mizaçla dolu olarak dirilecektir. Bu başlık altında sanat eserindeki kusura da değinen yazar, XVIII. yüzyılda ortaya çıkan harabelerin estetiği konusuna da geniş yer vermiştir.

Onuncu bölümün başlı̆ı Sır Hakkında Bazı Açıklamalar'dır. Sır açıklanmayan, açıklanmaması gereken bilgidir. Açıklanırsa açıklayana veya açıklanana bir zarar getirebilir. Tarih boyunca sırları çalmak için casuslar, korumak için kriptoprafiler geliştirilmiştir. Yine diğer bazı bölümlerde olduğu gibi alt başlıklara yer verilmiştir. İlki Sakınım'dır. Hastalıklarını, cinsel eğilimlerini, kökenlerini ifşa etmekten kaçınanlar vardır. Bunlar sakınıma girmez. Sakınımı anlatmak için Kardinal Mazzarino'nun Siyasetçilerin Elkitabı'ndan bir kesit yer veren U. Eco, bunu paranoyak bir sakınım olarak ele almıştır. Sırrın sahibinin ölümüyle yok olan sırların da sakınıma dahil edileceğini söyler. Modern çağda kitlesel iletişimin insanları sakınımdan vazgeçirip teşhirciliğe getirdiği görülmektedir. Bunu sağlayan da dedikodudur. Dedikodunun aynı zamanda şöhret de sağladığını gören bazı kişilerce fısıldanan dedikodu haykııımaya başlandı. İnsanlar bu çağda sakınımı terk ettiklerinin farkındadırlar ancak bunu önemsemezler. Bir diğer alt başıık Gizemli Sır'dır. Bu başlık altında sakınım dönemi bitse bile gizemli sırların hala var olduğu söylenir. Bunun Gülhaç başlığını taşıyan uzunca bir kısım takip eder. 
On birinci bölüm Komplo başlığını taşımaktadır. Komplonun geçmişte de bugün de en büyük saplantılardan biri olduğu söylenir. Komplolar kaygı verici olayların üzerine yapılan açıklamaların kişileri tatmin etmemesinden doğmaktadır. Bunların ardından komplo konusunda bir literatür taraması yapan U. Eco, 11 Eylül olayları, Lincoln ve Kennedy suikastları üzerinden uzun açıklamalara ve örneklemelere yer verir.

On ikinci ve son bölüm ise Kutsal Olanın Temsili başlığını taşımaktadır. Bu başlık altında öncelikle mutlak ve kutsal arasında ayrıma yer verilmiştir. Ardından kutsal, acizlik, bağımlıık, güçsüzlük ve sonsuz karşısındaki hiçli duygusu şeklinde tanımlanmaktadır. Kutsal olanın varlığı tanımlamasa da ona biat edilir, kurban sunulur. Bazen kutsal olan insanlar tarafından görülmek istenir ve buradan hiyerofani ihtiyacı, yani kutsalın insanlar için anlaşılır hâle gelmesini sağlayan görünür biçim doğar. Kutsalın varlığını deneyimleyen, kutsalla konuşabilmek için onu görmeyi diler. Göremezse geriye hayret, şaşkınlık, allak bullak olma ve korku kalır. Basit zihinler kutsal olanı insanî veya hayvanî forma büründürürler. Bu bazen totem imgesi olarak bazen de antropomorfik biçim atfedilerek yaşanır. Bazıları görmek ve konuşmak için put ve eklenti gibi imgelere büründürürler. Bu bölümde Ockham'ın görüşlerine de yer verilmiştir. Ayrıca mistiklerin ve kadınların da kutsal olana bakışına değinilmiştir. Bölüm ve kitap kutsal olanın tarihsel çağ ve zamanın sanatçılarının zevklerine göre nasıl farklı şekillere büründüğü ile tamamlanmıştır.

Umberto Eco'nun Milano Dersleri adı altında yayımlanan söz konusu eserinde yer alan 12 müstakil başlık birbirinden kopuk gibi görünse de pek çok açıdan birbirine yakın konulardır. Hemen her başlık altında en eski dönemlerden bugüne kadar söz konusu kavramın dönüşümüne yer veren yazar, sadece biri hariç 11 başlığı da görsellerle destekleyerek konunun daha iyi anlaşılmasına zemin hazırlamıştır. Ele aldığı konular hakkında genellikle önce bir literatür taraması yapmış, ardından kendi görüşlerine yer vermiştir. Çeşitli eserlerden aldığı örneklerle de görüşlerini destekleyen yazar bazen de kendi eserlerinden örneklere yer vermiştir. Ayrıca ele aldığı konuya tek yönlü bakmamış, konuyu sanatın çeşitli kollarından örnekler ile desteklemiştir. Bu açıdan bakıldığında Umberto Eco'nun Devlerin Omuzlarında adlı eseri ele aldığı konular için bir giriş niteliğindedir. Konu hakkında araştırma yapacak okuyucuya hem verdiği bilgilerle hem de yer yer dikkat çektiği konu hakkındaki önemli eserler ile yeni ufuklar açacaktır. 


\section{Kaynakça}

Eco, U. (2006). Güzelliğin Tarihi (A. C. Akkoyunlu vd. Çev.). İstanbul: Doğan Kitap. . (2009). Çirkinliğin Tarihi (A. U. Ergül, Ö. Çelik vd. Çev.). İstanbul: Doğan Kitap. . (2014). Düşman Yaratmak ve Rastgele Yazılar (L. T. Basmacı Çev.). İstanbul: Doğan Kitap. (2019). Devlerin Omuzlarında (E. Y. Cendey Çev.). İstanbul: Doğan Kitap.

Holbrook, V. R. (2008). Aşkın Okunmaz Kıyıları (E. Köroğlu, E. Kılıç Çev.). İstanbul: İletişim Yayınları. Özay Diniz, Y. (2017). Evliyâ Çelebi'nin Acayip ve Garip Dünyası (1. bs). İstanbul: Yapı Kredi Yayınları. Rosenkranz, K. (2018). Çirkinin Estetiği (M. Özdemir Çev.) İstanbul: Muhayyel.

http://www.lamilanesiana.eu/edizioni/2019/storia.html (e.t. 10.09.2019). 
